\title{
MASA DEPAN KARYA SENI MEDIA BARU
}

\author{
JASNI DOLAH *
}

\begin{abstract}
Abstrak
Perkembangan teknologi komputer terutamanya dalam bidang seni media baru menunjukkan kemajuan pesat sejak kebelakangan ini. Dari kaedah tradisional ke teknik-teknik moden dalam menghasilkan karya seni media baru telah mengakibatkan proses penghasilan karya menjadi lebih mudah dan cepat. Dalam bidang pendidikan, banyak universiti dan kolej menjadikan kursus media baru sebagai satu kursus yang menjadi pilihan ramai. Tetapi persoalannya apakah sumbangan yang dibuat melalui bidang ini benarbenar dapat menyumbang kepada pembangunan manusia secara amnya terutama dari segi pemikiran dan jati diri? Adakah dengan penggunaan teknologi komputer dalam menghasilkan karya dapat memberi impak sebenar kepada masyarakat sekeliling? Kertas ini membincangkan secara terperinci definisi seni media baru, isu-isu semasa, faedah, sumbangan serta cadangan yang boleh menyumbang kepada perkembangan dalam bidang ini terutama dalam konteks pendidikan di Malaysia.
\end{abstract}

Kata Kunci: Seni Media Baru, Teknologi, Masa Depan

\begin{abstract}
Development of computer technology, especially in the field of new media art has shown a significant progress in recent years. The progress from traditional methods to modern techniques in the production has resulted in the production process becoming easier and faster. In education, many universities and colleges make a new media course as a course of choice. But the question is whether the contribution made by this sector can really contribute to human development in general, especially in terms of critical thinking and self-identity? Does the use of computer technology can have an impact to the surrounding communities? This paper discusses in detail the definition of new media arts, contemporary issues, benefits, contributions and suggestions that can contribute to progress in this field, especially in the context of education in Malaysia.
\end{abstract}

Keywords: New Media Arts, Technology, Future

Jasni Dolah: PhD, Pensyarah Kanan di Pusat Pengajian Seni, Universiti Sains Malaysia 
Perkembangan teknologi komputer terutama dalam bidang Seni Media Baru menunjukkan kemajuan pesat sejak kebelakangan ini. Dari kaedah tradisional ke teknik-teknik moden dalam menghasilkan karya Seni Media Baru telah mengakibatkan proses penghasilan karya menjadi lebih mudah dan cepat. Dalam bidang pendidikan, banyak universiti dan kolej menjadikan kursus media baru sebagai satu kursus yang menjadi pilihan ramai. Tetapi persoalannya apakah sumbangan yang dibuat melalui bidang ini benar-benar dapat menyumbang kepada pembangunan manusia secara amnya terutama dari segi pemikiran dan jati diri?

\subsection{Definisi karya Seni Media Baru}

Seni Media Baru ditakrifkan sebagai hasil karya yang dihasilkan dengan menggunakan bantuan teknologi komputer yang melibatkan proses pengedaran secara digital dan dipersembahkan secara pameran. Networkedblogs mendefinisikan Seni Media Baru sebagai karya seni yang menggunakan teknologi komputer sebagai perantaraan penting bagi menghasilkan elemen-elemen kreatif dan dipamerkan secara persembahan. Sejak tahun 1970, pelbagai nama telah digunakan untuk menggambarkan proses pembuatan Seni Media Baru ini termasuklah seni komputer dan seni multimedia.

Hasil perkembangan teknologi komputer dalam menghasilkan seni media baru telah mengubah cara penghasilan karya sebelum ini seperti lukisan, gambar dan patung dihasilkan, sementara bentuk-bentuk baru, seperti seni di internet, seni instalasi digital, dan virtual reality, telah diakui menjadi cara praktikal yang artistik. Pengkarya seni media baru digambarkan sebagai seorang yang memanfaatkan teknologi komputer (digital) dalam produksi karya seni mereka. Hasil penggabungan antara seni dan teknologi ini mengakibatkan ramai yang telah cuba menjadikan teknologi komputer sebagai sebahagian daripada alat bantuan dalam menghasilkan hasil karya mereka.

\subsection{Tradisional vs Moden}

Perkembangan Seni Media Baru harus dilihat pada kontek tradisional peredaran zaman yang mendasari perkembangan hasil karya seni di Malaysia. Jika dahulu, proses penghasilan setiap karya dilakukan dengan penuh tradisi serta teliti, tapi kini ianya dapat dilakukan secara pantas dan cepat. Persoalan di sini menjurus kepada tahap penghasilan karya secara tradisional lebih bersifat artistisk kerana cetusan idea datang terus dari minda pengkarya. Penghasilan secara moden terlalu bergantung kepada penggunaan komputer dan sering dilihat sang pengkarya terlalu bergantung kepada penggunaan teknologi komputer.

Kemampuan manusia dalam menzahirkan sesuatu karya sedikit sebanyak bergantung kepada 
pengetahuan, pengalaman serta persekitaran dimana mereka tinggal. Seperti yang digariskan oleh Alvin Toffler (1970), kemampuan menyerap kejutan perubahan merupakan antara rencah asas yang digariskan oleh beliau dalam melihat kemampuan manusia dalam menerima gelombang perubahan. Individu, organisasi dan institusi pendidikan boleh diserang dengan beban perubahan mendadak yang boleh menimbulkan situasi ketidakseimbangan dalam membuat langkah penyesuaian yang bijak. Untuk itu beliau menuntut perubahan yang drastik dari segi bagaimana kreativiti dapat bergabung dengan teknologi komputer dapat dilakukan.

Kesedaran terhardap pendekatan moden dalam penghasilan karya seni media baru adalah penting seiring dengan perkembangan teknologi komputer itu sendiri. Kuasa memulakan perubahan didalam persekitaran serba canggih merupakan cabaran getir yang perlu dihadapi oleh negara Malaysia amnya. Para pengkarya seharusnya berani untuk menerokai media baru yang serba canggih dalam menyampaikan isi hati serta persoalan dalam karya mereka.

Aliran kemasukan seni elektronik di negara kita muncul akibat ledakan daripada gelombang kecanggihan. Pameran seni elektronik pertama tempatan telah berlangsung pada tahun 1997 yang menyaksikan himpunan karya-karya elektronik seperti seni komputer, seni cahaya dan seni video (Rahman \& Khairul),. Gaya pengucapan elektronik telah menjadi pilihan dalam mempamerkan karya dalam kalangan artis baru pada masa itu. Pameran ini telah memberi satu bukti bahawa aliran seni tempatan telah mengalami perubahan.

\subsection{Isu-isu dalam Seni Media Baru}

Semua bidang pada masa kini mengalami peralihan, tidak kiralah dalam konteks politik, ekonomi mahupun sosial. Cabaran globalisasi telah banyak mengubah pemikiran dan kehidupan manusia sejagat. Seiringan dengan itu, aliran kemasukan sains dan teknologi juga mempengaruhi pelbagai aspek termasuklah perkembangan seni tampak di Malaysia. Melalui perkembangan seni tampak dilihat perubahan berlaku melalui penerokaan dan penyelidikan dalam seni. Sebelum kedatangan gelombang globalisasi melanda, artis lebih selesa mempraktis menggunakan teknik konvensional sahaja untuk menyalurkan idea. Namun senario ini telah berubah. Perkembangan teknologi yang bergerak pantas telah membawa kepada pergerakan dalam minda dan pemikiran untuk menjana suatu idea yang baru dengan mencipta pembaharuan. Pada amnya hasil seni media baru dihasilkan sama ada untuk kepuasaan mahupun untuk melepaskan persoalan-persoalan yang terbuku di dalam hati sang pengkarya.

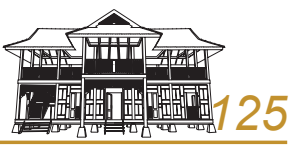


Banyak karya terhasil bersifat ekperimental atau terlalu minimalis. Dilihat juga karya-karya yang dicipta atas alasan untuk bereksperimen atau hanya bersifat mencuba. Isu-isu ini boleh dibahagikan kepada beberapa bidang seperti yang dinyatakan di bawah ini.

\subsection{Krisis Intelek dan Sistem Nilai}

Arus globalisasi yang mencanangkan dunia tanpa sempadan dan penggunaan ICT terutama sekali Internet telah merubah cara dan corak pengkaryaan hasil-hasil seni. Kapitalisme global dan ledakan revolusi ICT ini telah membuka jalan kepada situasi dan pemikiran pascamoden (Salleh Yaapar, 1996). Keadaan ini telah mengakibatkan kepada krisis intelek dan sistem nilai yang sangat kritikal dan kompleks. Kesemua ini telah dimulakan dengan pertembungan antara pemikiran dengan nilai pra-moden, moden dan kini pascamoden.

Kapitalisme global dan ledakan ICT ini telah menjadi katalis dan saluran perang saraf yang bersempadan. (Abdul Rahman Embong dan Cooper, 1998). Muhammad Uthman dalam eseinya yang bertajuk "Pascamodenisme dan Islam: Satu Pandangan Awal" telah menyatakan bahawa kehadiran pascamoden perlu ditangani menerusi perspektif dan nilai Islam. Benjamin (1970) telah menyatakan tentang kehilangan nilai dan keaslian akibat penyalinan mekanikal dari kamera foto.

Neil Postman (1985) seterusnya mengkritik kemabukan budaya tontonan yang hadir daripada hiburan massa, terutama yang disalurkan melalui televisyen. Struktur dominasi media global seperti televisyen, video, filem dan media cetak telah membentuk dan merubah wajah dunia menjadi kampung sejagat dengan nilai tiruan serta unsur homogeny yang berpaksi barat (Macluhan dan Powers, 1989).

Dilihat hasil pengkaryaan di Malaysia lebih menjurus kepada penciptaan estetika yang berasaskan pengalaman dasar suci daripada tradisi (Ismail, 1995). Menurut beliau untuk menjalani kehidupan secara tradisi dimasa depan, kita bukan sahaja memerlukan kepandaian dalam tradisi tetapi juga ketokohan dalam teknologi dan media yang menjadi pengantarnya. Wan Zawawi (2000) pula meninjau keutuhan nilai dan jati diri budaya kebangsaan dalam realiti multibudaya dan fragmentasi pascamoden. Pemusatan takrifan budaya yang dibentuk dalam Dasar Kebudayaan Kebangsaan perlu 'bertanding' dengan bentuk nilai 'tidak rasmi' yang lain 
atau serpihan yang dibekalkan oleh media elektronik.

\subsection{Dasar Falsafah dan Strategi Pelaksanaan Pendidikan Seni Rupa}

Perkembangan teknologi ICT yang berkembang pesat telah menyebabkan pelaksanaan dasar falsafah dan strategi pendidikan seni rupa di Malaysia menghadapi sedikit kesukaran. Persoalan bagaimana ianya dapat membantu pembetukan generasi bermaklumat yang mampu menghadapi krisis ini dengan matang dan bertanggungjawab. Perkembangan dasar serta strategi sedikit sebanyak berkait dengan kesan yang ditinggalkan oleh penjajah terhadap Malaysia. Begitu juga perkembangan ICT dilihat sebagai lanjutan imperialisma Barat yang seterusnya menanam kefahaman pascamoden pula. Dilihat perkembang era maklumat memerlukan penglibatan multidisplin terutama dari bidang-bidang kesenian dan kemanusiaan yang semakin terpinggir.

Seperti yang dinyatakan oleh Zerzan dan Carnes (1988), kedudukan teknologi sebagai alat penguasaan kapitalisma global dan lanjutan imperialisma budaya yang hanya berpaksikan kepentingan nilai ekonomi melebihi segalanya. Situasi ini disokong oleh Bill Joy dalam bukunya "Why The Future Doesn't Need Us" menyatakan bahawa dalam perubahan teknologi yang pantas akan menyebabkan kepupusan manusia dalam jangka masa dua generasi mendatang melalui kemajuan teknologi yang tidak mempunyai sebarang hala tuju yang pasti.

Keadaan ini amat bersesuaian sepertimana dinyatakan oleh Ismail Zain (1995), buku dan celik huruf itu sendiri pernah dianggap sebagai pembunuh tradisi lisan yang mendasari pemikiran masyarakat pra-moden. Ini jelas dapat dilihat melalui ahli falsafah Socrates yang pernah menolak 'kerja menulis' yang dihasilkan oleh anak muridnya iaitu Plato. Menulis dianggapnya sebagai alat bantu memori sahaja dan bukannya pengetahuan berasaskan realiti (Vethoven, 1990).

\subsection{Kursus-kursus Seni Media Baru di peringkat kolej dan universiti di Malaysia.}

Perkembangan ICT yang pesat menyebabkan berlakunya pertumbuhan dan penawaran kursuskursus yang menjurus kepada bidang seni media baru. Niranjan Rajah (1998) dalam eseinya

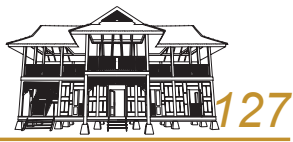


bertajuk "Art Education in A Climate of Convergence" memberikan suatu pandangan kritikal yang sangat relevan dengan keperluan ICT terutama dalam pendidikan seni. Salah satu persoalan yang ditimbulkan adalah apabila penerapan ICT hanya berpaksikan pasang surut ekonomi global serta kecanggihan dan khayalan teknologi semata-mata, kesan budayanya hanya akan melanjutkan beberapa polemik perubahan. Hasilnya lebih meletakkan dimensi kesenian sebagai budak suruhan semta-mata. Penekanan terhadap paksi material ini perlu diseimbangi oleh pendekatan dalaman (Intrinsic Touch).

Penubuhan sekolah seni yang pertama di Johor dan Sarawak telah di putuskan dalam persidangan perancangan strategik KPM pada tahun 2004. Melalui penubuhan sekolah seni ini diharapkan supaya pihak KPM dapat membangunkan potensi individu secara seimbang dan bersepadu melalui pendidikan kesenian yang dilaksanakan secara terancang dan sistematik. Usaha ini adalah bagi melahirkan insan yang bertanggungjawab dan berkeperibadian mulia dalam mengamalkan budaya bangsa yang luhur dan beridentiti Malaysia. Penubuhan sekolah seni ini dianggap bertepatan dalam memartabatkan bidang seni secara keseluruhannya.

Pertumbuhan pesat dan persaingan dari IPTA dan IPTS melalui pembelajaran terbuka, penawaran program berkembar, e-book, e-library dan tuntutan terhadap para pensyarah dalam melengkapkan diri dengan kemahiran ICT telah menjadi lumrah terkini. Ini dapat dilihat melalui penawaran demi penawaran diperingkat universiti dan kolej dalam menawarkan kursus-kursus media baru. Program-program seperti Media Baru, Kreatif Multimedia, Rekabentuk Grafik dan Animasi tumbuh seperti cendawan. Lambakan kursus baru ini telah menyebabkan hampir keseluruhan program yang ditawarkan adalah bersifat 'Cut and Paste' dan tidak mempunyai kekuatannya yang tersendiri.

\subsection{Permintaan di peringkat industri kreatif}

Permintaan terhadap graduan dalam bidang media baru semakin meningkat sejak akhir-akhir ini. Keadaan ini mungkin disebabkan kreativiti serta kemahiran yang dimiliki oleh seseorang pelajar tersebut menjadi pilihan para syarikat memilih mereka menjadi salah seorang tenaga kerja. Menurut artikel dalam mileniaonline.com, Menteri Pendidikan 11, Datuk Seri Idris Jusoh berkata, industri kreatif negara mampu berkembang kepada RM33 bilion menjelang tahun 2020 berbanding sekarang baru RM9.4 bilion. Beliau berkata, kejayaan industri kreatif ini kerana 
komitmen tinggi kerajaan menerusi penyediaan program dan dana. Sebagai contoh sejumlah RM200 juta disediakan di bawah Dasar Industri Kreatif Negara yang dilancarkan Perdana Menteri pada 2010. Langkah kerajaan itu kerana menyedari industri kreatif berpotensi berkembang maju di peringkat global. Walaubagaimanapun lambakan graduan dalam bidang ini menyebabkan berlakunya jurang kualiti graduan yang tinggi dimana tidak semua mempunyai kualiti yang dikehendaki oleh majikan.

\subsection{Masa Depan karya Media Baru}

Peranan yang dimainkan dalam karya-karya media baru amat terbatas kepada bidang-bidang tertentu sahaja. Dari kaedah tradisional kepada penggunaan bahan secara digital telah memungkinkan segala bentuk kreativiti dapat dicurahkan dalam bentuk hasil karya. Namun, keaslian hasil karya telah menjadi persoalan dan melampaui norma batasan yang menjadi tunjang pengkaryaan. Pengkarya lebih bersifat individualistik dan sering berekperimentasi dengan dunia tersendiri. Permasalahan harian serta isu-isu sejagat menjadi tidak penting kerana ideologi mereka menjadi terlalu egoistik.

Karya-karya mereka berkembang mengikut teknologi semasa dan melupakan norma-norma yang sepatutnya digarapkan dalam menghasilkan karya. Seharusnya perkembangan teknologi menjadi pemangkin kepada pengkarya media baru untuk menjadi lebih bertanggungjawab dalam karya mereka. Karya-karya yang hebat bukan saja nampak cantik malah mempunyai nilai-nilai positif yang boleh digunakan oleh masyarakat sekelilingnya. 


\section{Rujukan}

TENIAT: International Journal of Creative Futures and Heritage, Vol. XX, Issue No. X

ISSN : 2289-4527

http://networkedblogs.com/hQgJI

Saidon, Hasnul, 2003, Cabaran Praktis Seni Elektronik Dalam Era Maklumat, Wacana Seni Journal of Arts Discourse. Jil./Nol. 2

Abd Rahman, Khairul Aidil Azlin, Seni Hibrid: Pergerakan Seni Visual Alternatif di Malaysia.

Salleh Yappar. 1996. "Pemikiran Pasca-Modernisme." Pemikir Jan - Mac

Abdul Rahman Embong dan Robert Cooper. 1998. "Pramoden, Moden dan Pasca Moden", Pemikir, Julai - September.

Benjamin, Walter. 1970. "The Work of Art in the Age of Mechanical Reproduction" dalam W. Benjamin (ed.), Illumination. Great Britain: Fontana / Collins.

Postman, Neil. 1985. Amusing Ourselves to Death: Public Discourse in the Age of Show Business. New York: Penguin.

Mcluhan, MArshal dan Powers. 1989. The Global Village: Transformations in the World and Media in the 21st Century. Oxford: Oxford University Press.

Ismail Zain. 1995. "Masa Depan Tradisi - Dikhususkan Kepada Pengalaman Kuno di Malaysia" dalam Ismail Zain Retrospective. Kuala Lumpur: National Art Gallery.

Wan Zawawi Ibrahim. 2000. "Anthropologising with National Culture in Malaysia: Representing and Contesting Culture in the Age of Fragmentation". Finnish Anthropology, Special Issue 2.

Zerzan, John dan Carnes, Alice (eds.) 1988. Questioning Technology: A Critical Anthology. London: Freedom Press.

Ismail Zain. 1995. "Masa Depan Tradisi - Dikhususkan Kepada Pengalaman Kuno di Malaysia" dalam Ismail Zain Retrospective. Kuala Lumpur: National Art Gallery.

Velthoven, William. 1996. Multi - Media Graphics. London: Thames \& Hudson

Ltd. 
Niranjan Rajah. 1998. "Art Education in a Climate of Convergence", Cipta - Cetusan Inspirasi Pelajar Tahun AKhir, UNIMAS.

http://mileniaonline.com/index.php/ekonomi/579-potensi-industri-kreatif-rm33-bilion-pada-2020 